\title{
Investigation and Analysis of College Students' Cognition in Science and Technology Competitions
}

\author{
https://doi.org/10.3991/ijet.v12i07.7226 \\ Hongwei Yue \\ Wuyi University, Jiangmen, China \\ Ken Cai * \\ Zhongkai University of Agriculture and Engineering, Guangzhou, China \\ icken@ $126 . \mathrm{com}$ \\ Yibin $\mathrm{Yu}$ \\ Wuyi University, Jiangmen, China \\ Yihong He \\ Wuyi University, Jiangmen, China \\ Yingying Jin \\ Wuyi University, Jiangmen, China
}

\begin{abstract}
Science and technology competitions are an important platform to verify the use and improve the mastery of professional knowledge of college students. These competitions are also important in enhancing the comprehensive quality and ability of these students. To highlight the role of science and technology competitions in cultivating the comprehensive ability of undergraduates, this study designed questionnaires on college students' cognition in science and technology competitions. In this study, the reliability of the questionnaire was tested and factor analysis method was used to explore the influencing factors of competition cognition under the premise of ensuring the reliability of the questionnaire. According to the results of the analysis, to enhance the training ability of students, positive interactions between teachers and students are promoted through a network-based contest using the WeChat public platform to build a virtual contest environment. Results show that the WeChat teaching platform can gradually improve students' independent innovation ability. These conclusions are helpful to understand the participation situation and existing problems in such competitions, and to provide a useful reference on how to actualize the role of science and technology competitions.
\end{abstract}

Keywords - science and technology competition, undergraduate education, WeChat contest platform, questionnaire, SPSS statistical software 
Paper-Investigation and Analysis of College Students' Cognition in Science and Technology Compe...

\section{Introduction}

Undergraduate education is the main way to cultivate high-level innovative talents, which is significant in construction a national innovation system. With the expansion of the enrollment scale of higher education, education authorities and scholars believe that the quality of undergraduate education still needs improvement. A survey shows that undergraduates participate in more than $58 \%$ of scientific research projects [1]. Experts have pointed out the wide gap between the innovation ability of undergraduate students in China and the demand for innovation. Thus, how to cultivate the innovative ability of undergraduate students has become an important issue that concerns educators and researchers.

The key to improve the quality of undergraduate education is to cultivate the innovative ability of undergraduates. This ability reflects their aptitude in generating novel, useful, or potentially useful ideas, as well as related products, procedures, and processes. Science and technology competitions are among the many ways to cultivate the innovative ability of undergraduate students in universities. Such competitions can also enhance the students' active learning ability by requiring them to conduct meaningful learning tasks and think about what they are doing [2].

\section{State of the Art}

According to the literature in this field, the research on the innovation ability of undergraduates mainly focuses on the following problems: connotation of the innovation ability of undergraduates $[3,4]$, how to evaluate the innovation ability of undergraduates [5,6], and influence factors of innovation capability of undergraduates $[7,8,9]$. Considering the many factors that influence the innovation ability of college students, some scholars, starting from the angle of scientific research activity participation, have analyzed the advantages of college students' participation in scientific research activities of their academic advisors to measure the students' competitiveness. Studies on undergraduate research experiences indicate that scientific research activities lead to a wide array of benefits for students [10,11].

Many scholars have conducted research on the importance of a discipline competition to cultivate undergraduate competitiveness [12]. However, the literature on the discipline competition in China mainly focuses on the following two questions: one is the study of the role of the discipline competition, and the other is the research on the system of discipline competition. First, regarding the literature on the role of discipline competition, most studies by domestic scholars emphasize the promotion of innovative talent training. For example, Yang Zhidong [13] discussed the training mechanism of discipline competition, analyzed the function of discipline competition in cultivating the consciousness of problems and improving analytical ability. Zhang Ziyan [14] believes that the discipline competition has the same goal as talent training, which is to improve the overall quality of students, cultivate innovation ability, solve practical problems, and stress the highlights of thinking; he believes that the discipline competition is an effective way to train high-quality and innovative talents. 
Some scholars also point out that the discipline competition plays an important role in constructing a study style. They think that the discipline competition is advantageous to raise students' learning initiative as well as their team cooperation and competition consciousness; being helpful to student individuality development and innovation spirit, such a competition establishes good study habits [15]. Second, regarding the research on the system of discipline competition, some scholars have proposed a discipline competition reform system to construct four levels, namely, college and university, prefecture, provincial, and national levels, and to cultivate three dimensions called basic skills, comprehensive ability, and innovation ability. Shen Xiu [16] proposed the construction of a scientific, standardized, and effective scientific competition operating mechanism from three dimensions of basic quality, professional comprehension, and innovative entrepreneurship. Zhuang Jianjun [17] explored the organization and management of discipline competition mechanism from the perspective of university management.

To sum up, the research on the innovation ability of college students in our country mainly focuses on the connotation, evaluation, influencing factors, and training ways of college students' innovation ability. Among these topics, the training mode is the research hotspot. Most of the studies on the discipline competition focus on the cultivation of the innovative talents and the function of training of practical talents as well as the construction of the discipline competition system. Thus, in the vigorous development of discipline competition today, when undergraduate innovation ability is in urgent need of improvement, only a few studies are oriented toward university students and focus on the impact of discipline competition on the innovation ability of undergraduates. The research on the status of college students' participation and cognition on discipline competition is the focus of this study. The understanding of college students' views on discipline competition and their participation condition can help us understand the current situation and existing problems of discipline competition and lay a foundation for exploring how to conduct discipline competition and specify the effective strategies to cultivate the innovation ability of undergraduates.

The remainder of this work is structured as follows. Section 3 discusses the questionnaire using SPSS. The WeChat platform is reported in Section 4. Finally, the concluding remarks are provided in Section 5.

\section{Design and Analysis of the Questionnaire}

Investigating the status of college students' participation and cognition on discipline competition is the most effective way to understand the subject. The objects of this investigation are college students in general and college students who have participated in the discipline competition. Taking Wuyi University as an example and referring to a large number of related studies combined with interview results of experts, we designed a questionnaire for majority of the college students and conducted statistical analysis of the questionnaire using SPSS. 


\subsection{Investigation ways}

The questionnaire survey was the main method used in the investigation. A total of 500 questionnaires were designed. The main problems involved in the questionnaire involves the college students understanding of innovation ability and discipline competition, basic participation situation, participation motivation, influence of discipline competition on ability to innovate, and understanding and opinions of knowledge application ability improvement. The main process of the questionnaire is shown in Fig.1.

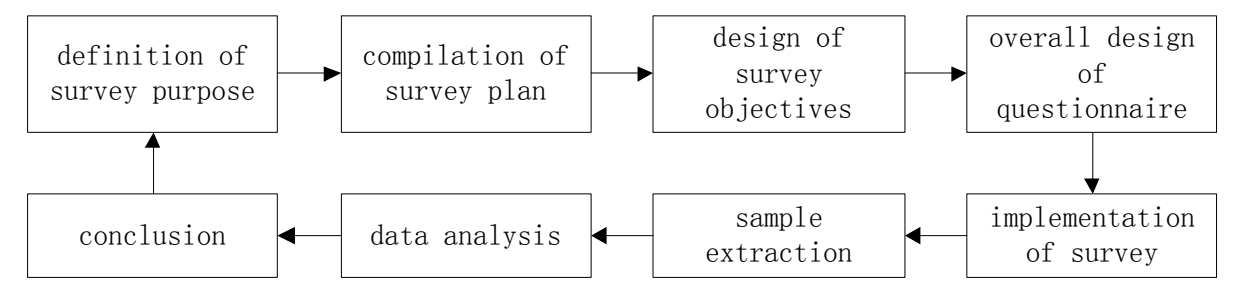

Fig. 1. Main process of questionnaire survey

To gain a better understanding of college students' cognition of discipline competition, 500 samples were randomly selected from sophomores and juniors in the School of Mathematics, College of Information Engineering, and School of Computing at Wuyi University for questionnaire investigation. Finally, 495 questionnaires were returned and 11 were rejected because of lack of information. Among these questionnaires, 484 were effective. Among the effective questionnaires, 124 were accomplished by college students who had taken part in a discipline competition. The overall effective rate was $96.8 \%$. The number of valid questionnaires exceeds the minimum sample size required for a simple random sampling with a confidence coefficient of $95 \%$ and a maximum permissible error of less than $7 \%$.

\subsection{Reliability analysis of questionnaire}

Reliability analysis aims to estimate and measure the reliability of the questionnaire. Four types of commonly used questionnaire reliability analysis methods are available, namely, test-retest reliability method, alternate-form reliability method, split-half reliability method, and Cronbach's alpha $(\alpha)$ reliability coefficient method. Among these methods, the Cronbach's $\alpha$ reliability coefficient method is most suitable for the reliability analysis on the attitude and opinion questionnaire. Therefore, this paper analyzes the reliability of the questionnaire by using this method.

According to reference [18], if $\alpha=0.7 \sim 0.8$, although some problems exist in the questionnaire design, the questionnaire retains some reference value. If $\alpha>0.8$, the intrinsic reliability of the questionnaire is high. According to the $\alpha$ reliability coefficient analysis method, SPSS (version 19.0) should be used as a computing platform to obtain the reliability analysis results of this questionnaire, as shown in Table 1. The 
table shows that the total reliability coefficient of the whole scale is 0.857 , which indicates that the scale has good internal consistency and high reliability.

Table 1. Reliability analysis results of scale

\begin{tabular}{|c|c|c|}
\hline \multicolumn{3}{|c|}{ Reliability statistics } \\
\hline Cronbach's Alpha & Cronbach's Alpha Based on Standardized Items & K of Items \\
\hline 0.849 & 0.857 & 11 \\
\hline
\end{tabular}

\subsection{Descriptive statistical analysis of questionnaire}

In the questionnaire design, the factors related to the discipline competition of college students are divided into 11 measurement dimensions (factors). And The questionnaire uses a five-point Likert scale and sets five options, namely, "very important," "more important," "general," "less important," and "not important" for evaluation based on various factors.

The descriptive analysis is presented in Table 2. Descriptive statistics show that the average value of most factors is more than 3.5, indicating that most of the college students participating in the survey believe that each factor involved in this questionnaire is very important. The average score of "scientific research participation" factor is the lowest, and the corresponding standard deviation is the highest, which shows that respondents, to a large extent, have a different understanding of the relationship between scientific research participation and discipline competition of college students, and the corresponding importance recognition is relatively low.

Table 2. Questionnaire survey of college student participation in discipline competition

\begin{tabular}{|l|c|c|c|c|c|}
\hline \multicolumn{1}{|c|}{ Factor } & Min. value & Max. value & Mean value & Standard deviation & Variance \\
\hline Personal interest & 2 & 5 & 4.30 & 0.757 & 0.573 \\
\hline Material reward & 2 & 5 & 3.97 & 0.877 & 0.769 \\
\hline Personal reputation & 2 & 5 & 3.84 & 0.912 & 0.832 \\
\hline Value realization & 2 & 5 & 4.14 & 0.796 & 0.634 \\
\hline Comprehensive abilities & 1 & 5 & 4.29 & 0.803 & 0.645 \\
\hline Propaganda and mobilization & 1 & 5 & 4.45 & 0.824 & 0.679 \\
\hline Scientific research participation & 1 & 5 & 3.11 & 1.123 & 1.260 \\
\hline Teamwork & 3 & 5 & 4.34 & 0.714 & 0.510 \\
\hline Professional guidance & 1 & 5 & 4.13 & 0.853 & 0.727 \\
\hline Clear work division & 3 & 5 & 4.34 & 0.677 & 0.459 \\
\hline Clear process & 2 & 5 & 4.48 & 0.714 & 0.509 \\
\hline
\end{tabular}

\subsection{Factor analysis of questionnaire}

Through actual investigations, we often encounter a large amount of data. These data cannot guarantee the accuracy of analysis because of an excessive amount of information. Therefore, the factor analysis method is used to process the data and 
extract the important factors, which makes the information representative and highly general. This paper reclassifies the original data, determines the common factors with the same attributes by factor analysis method, and constructs a new suitable index system on participation in science and technology competition for college students. Orthogonally rotated component matrix is shown in Table 3 (for convenient observation, a value less than 0.50 is left out).

Table 3. Orthogonally rotated component matrix

\begin{tabular}{|l|c|c|c|c|}
\hline \multirow{2}{*}{ Factor } & \multicolumn{3}{c|}{ Component } & \multicolumn{1}{c|}{ 3 } \\
\cline { 2 - 5 } & 1 & 2 & & \\
\hline Personal interest & 0.654 & & & 0.814 \\
\hline Material reward & & & & 0.909 \\
\hline Personal reputation & & & & \\
\hline Value realization & 0.779 & & & \\
\hline Comprehensive abilities & 0.756 & & 0.822 & \\
\hline Propaganda and mobilization & 0.582 & & & \\
\hline Scientific research participation & & & & \\
\hline Teamwork & & 0.633 & & \\
\hline Professional guidance & & & & \\
\hline Clear work division & & 0.793 & & \\
\hline Clear process & & 0.748 & & \\
\hline
\end{tabular}

As shown in Table 3, four main factors are extracted from the questionnaire, which can be divided into four categories. The first common factor mainly reflects "the reasons and purposes of the competition participation". The sub-factors involved are personal interest, value realization, propaganda and mobilization, and comprehensive abilities. The second factor mainly reflects the importance of "cooperation and communication". The factors involved are teamwork, clear division of labor, and clear process. The third factor can be summed up as "ability training," which reflects that the participants need teacher intervention when participating in a certain ability training activity; otherwise, their enthusiasm for competition participation will be reduced. The fourth factor is summarized as "result oriented," and the factors involved are material reward and personal reputation, which reflect the motivation of college student participation in science and technology competitions. Each factor has a high load on its factors, thereby indicating that the scale has high construct validity.

\section{Design of Multimedia Competition Guiding Platform}

From the aforementioned comparative analysis, we can observe that the third factor, ability training, is closely related to teaching methods while the other three factors are often closely related to the competition system. The following is mainly a discussion of how to use the multimedia platform to improve the existing science and tech- 
nology competition teaching platform to increase the students' enthusiasm for participation through improvement of the ability training factor.

Using the WeChat multimedia platform can complete the diversified science and technology competition teaching methods effectively to improve the ability training factor. WeChat supports voice messaging, videos, images, and text, and is therefore suitable for most smartphones. Based on these features, the WeChat public platform is proposed to build the contest support environment to comply with the technical development and meet the application orientation of college students. On the WeChat teaching platform, the teacher establishes the teaching platform and provides the following modules: learning material, teaching activity organization, homework, and answer-and-interaction modules. Using the platform, students can check for learning updates, view resources and task lists at any time, undergo training and tests, and communicate in a timely manner with others. Contest organizers can use these WeChat functions to organize appropriate contest activities. Participants can then share and interact through voice information, video information, graphic information, and links, as shown in Fig. 2.

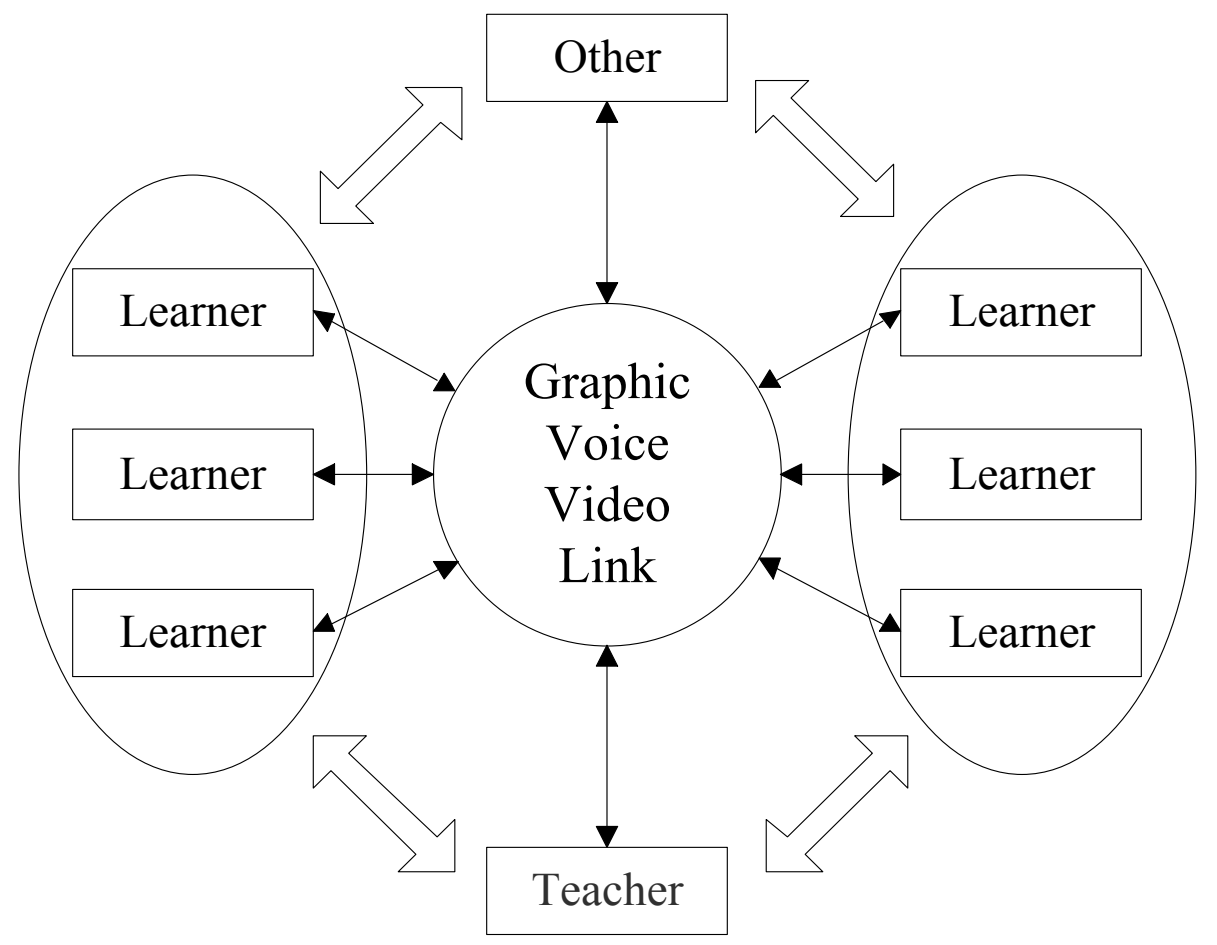

Fig. 2. Guiding platform based on the WeChat platform

This study takes as an example the National College Students' Smart Car Competition, an exploratory engineering activity that cultivates innovation and the pursuit of excellence. Figure 3 presents an objective picture of this competition. 


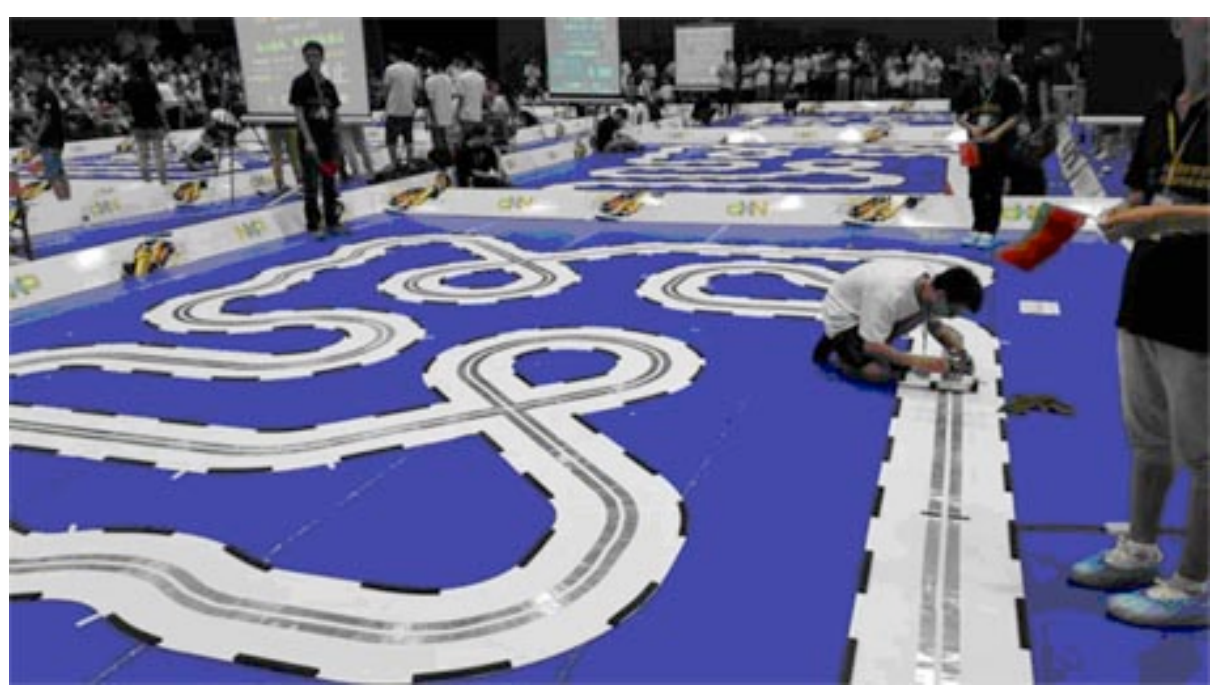

Fig. 3. Objective picture of smart car competition

To reduce teachers' workload and improve students' learning quality, the public WeChat platform is used by the instructor team to upload work videos on how to install smart cars onto the public server, to facilitate downloading or viewing by students at any time, to encourage students to raise questions, and to help teachers improve their tutorial efficiency. Using the learning video, students can rapidly master how to assemble smart cars and how to install and use mobile applications. Finally, actual movement of electric cars must provide a visual impact, arouse the interest of students, and break the inherent perspective that hardware is difficult to learn. The most commonly used functions of the public platform are given as follows:

Push service for multimedia information: Teaching tasks to direct competition may be decomposed according to various competitions. For example, the National College Students' Smart Car Competition is categorized as a photo-electricity group, camera lens group, electromagnetic group, and dual-car chasing group. Instructors are requested to collaborate on various topics, plan the teaching video, prepare courseware, and send text information. Figure 4(a) shows text information on the installation of smart cars available to all students. This feature may also serve as an accurate push for such information as chip use, tool list, and laboratory opening hours. In the functional analysis of the smart car module, the smart car consists of a single-chip microsystem, a power module, a toggle-switch circuit, a sensor module, and a motor-driven module.

Auto-response setting function: Students are requested to answer two types of questions in the process of preparing for the competition. The first type is related to basic rules, which account for $70 \%$ of the total questions and may be answered through textbook or online search. This function enables easy description with words, pictures, and messages, and is independent of teachers' subjective thinking; the answers include but are not limited to testing principles of the path of the camera and electromagnetic groups. The second type is about open and innovative questions, 


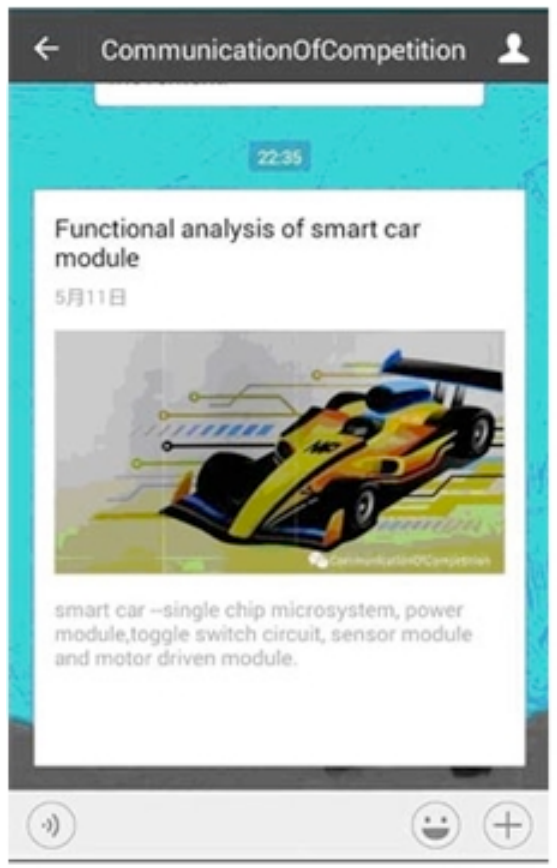

(a)

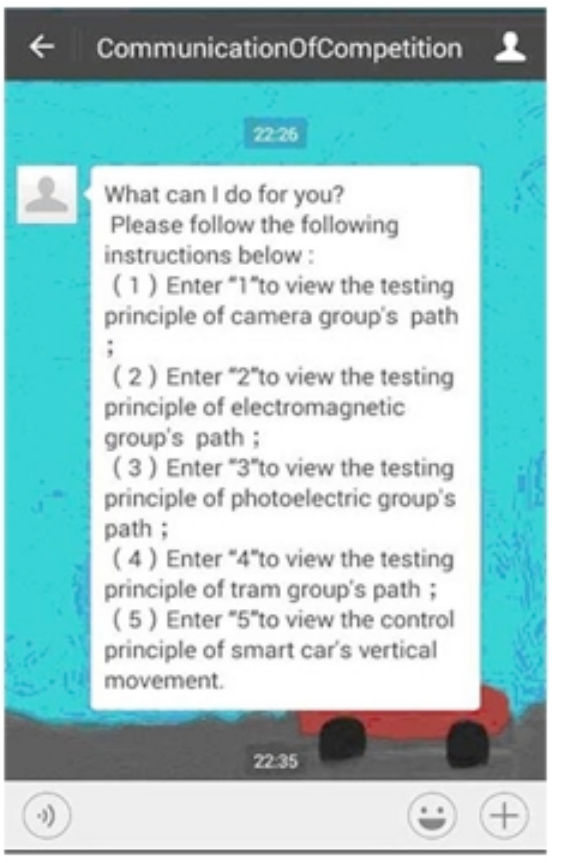

(b)

Fig. 4. Images of WeChat platform. (a) Text information on installation of smart cars, and (b) Auto-response function

which account for $20 \%$ of the total. Answers vary with different respondents, are not easy to describe with simple words and pictures, and are provided by respondents using all-around knowledge by means of drawings, words, and formulas. Specific to the first type of questions, the auto-response function on the public WeChat platform may significantly reduce teachers' workload in practical activities. Subjecting questions on basic rules to the WeChat system on a smart handset, the auto-response function on the public WeChat platform can perform a smart response to students' questions on basic rules, as shown in Figure 4(b), thereby relieving teachers from otherwise repeated labor.

In other words, according to the special rules and characteristics of science and technology competitions, conducting guidance on theoretical and practical knowledge for students in a short period of time is necessary. Therefore, careful course arrangement and convergence as well as knowledge point distribution and difficulty are important, and the application of multimedia technology plays a crucial role. Aiming at different competitions, the instructors extract several important points and difficult points in time for deep processing and use graphic images, audio, video, and other multimedia so that the students do not need group training but can learn in their own time. This approach is beneficial in cultivating a solid theoretical foundation and strong practical ability. 
Paper-Investigation and Analysis of College Students' Cognition in Science and Technology Compe...

\section{Conclusions}

To improve the college students' understanding of science and technology competitions, enhance the support system for such competitions, and actualize the competition's role in developing undergraduates' innovation ability, this study conducted a questionnaire survey that investigated the cognition of college students on science and technology competitions. The results were statistically analyzed, and the following conclusions were obtained:

1. The descriptive statistical analysis of the questionnaire data shows that the role of scientific research participation in students' ability training has not been widely recognized, which shows that the strength of scientific research in teaching is inadequate. Allowing the students to participate in the research activities of teachers is not only the best way to cultivate the practical ability and innovative consciousness of students but can also significantly improve their enthusiasm to learn theoretical knowledge, improve the efficiency of lectures, and boost the students' confidence in science and technology competitions.

2. The descriptive statistical analysis of the questionnaire data shows that propaganda and mobilization are the main ways to encourage student participation in the competition. However, due to the lack of understanding about this competition, its role is often ignored by undergraduates. Therefore, by using a variety of media, schools can carry out propaganda and mobilization for various competitions to promote a culture of scientific and technological interest on campus. Schools can organize campus science and technology festivals, a science popularization week and other activities, and encourage students to participate in these activities, listen to lectures of experts and immerse themselves in an atmosphere of innovation, which improves their understanding of science and technology competitions and is helpful to increase the degree of participation in these competitions.

3. The principal component analysis of the questionnaire data shows that to mobilize the enthusiasm of students to participate in science and technology competitions, the school should increase the awards.

4. The "ability training" factor can be enhanced using WeChat contest guiding platform. Using the WeChat contest guiding platform, instructors can design a variety of multimedia such as graphic images, audios, and videos according to different competitions. Furthermore, using the WeChat contest guiding platform, competitors not only can develop informal learning habits to achieve systematic learning in a fragmented time, but also provides a new contest interaction environment to improve teaching and learning.

This questionnaire is helpful to understand the problems in the organization of science and technology competitions in colleges and in the process of student participation, thereby providing a powerful reference to improve the innovation ability of college students. This paper also provides the practical teaching mode, which constructs the WeChat platform and uses digital multimedia technology to construct the teaching reform and the discipline competition. This approach has a high value of promotion to improve the development of the overall quality of students and strengthen their opera- 
Paper-Investigation and Analysis of College Students' Cognition in Science and Technology Compe...

tional and practical abilities. The future research direction focuses on how to improve the incentive mechanism and security system of science and technology competitions and how to perfect the relevant policy framework.

\section{Acknowledgment}

This work was supported by the "Twelfth Five-Year" Plan Youth Program of National Education Information Technology Research(No.146242186), the Guangdong Provincial Program for Elaborate Resource Sharing Course, the Cultivation Program of Educational and Teaching Achievement Prize in Guangdong Province, the Features Innovative Program in Colleges and Universities of Guangdong(No.2015KTSCX069 and No. 2015KTSCX148), the Pearl River S\&T Nova Program of Guangzhou (No.201506010035), the Project of Outstanding Young Teachers' Training in Colleges and Universities of Guangdong (No. YQ2015091), the Undergraduate Teaching Quality and Teaching Reform Project of Wuyi University(No. JX2016025).

\section{$7 \quad$ References}

[1] Peiyong, D. Analysis of research-oriented teaching and learning modes for cultivation of application-oriented innovative talents, Journal of Shandong Jianzhu University, 2012, vol.27(4),pp.440-450.

[2] Y. Chen, X.Peng and J. Sun. National undergraduate electronic design contest: A vehicle for enhancing active learning, British Journal of Educational Technology, 2010,vol.41(4),pp.660-664. https://doi.org/10.1111/j.1467-8535.2010.01096.x

[3] Baojie, X. Intensifying consciousness, perfecting system and cultivating students' innovative ability, Experimental Technology and Management,2013,vol.30(4),pp.1-3.

[4] Qiping, Tang. Rearch of graduate students' creative ability from the perspective of culture,Academic Degrees \& Graduate Education,2013,vol.2,pp.12-15.

[5] Zhang Yumei, Liu Guihua and Wang Heng. Impact of case-based learning on innovative ability of medical students, Medicine \& Philosophy(A),2013,vol.37(9),pp.87-89.

[6] Xinlai Dai, Tingting Wang. Research on collaborative cultivation of innovation educational technology undergraduates,Experimental Technology and Management, 2015,vol.32(8),pp.19-22.

[7] H. Zhu and D. An. Research on impact of teaching behavior on undergraduates' innovative ability-Based on the comparison between science and other subjects, Education Research Monthly, 2016,vol.20(1),pp.81-89.

[8] Y. Zhang, H. Liu, Jibao Gu. Research on impacht of graduate student motivation and social capital's on innovation ability,Academic Degrees \& Graduate Education,2014,vol.17(5),pp.47-52.

[9] H. Zhu, W. Li, Z. Zuo. The Status of Graduate Students' Creativity and Its Influence Mechanism,Journal of Higher Education, 2011, vol. 3(2) , pp. 74-82.

[10] Shortlidge, E. E., Bangera, G., Brownell, S. E. Faculty perspectives on developing and teaching course-based undergraduate research experiences, BioScience, 2016, vol.66(1), pp.54-62. https://doi.org/10.1093/biosci/biv167 
Paper-Investigation and Analysis of College Students' Cognition in Science and Technology Compe...

[11] Shanle, E. K., Tsun, I. K., Strahl, B. D. A course-based undergraduate research experience investigating p300 bromodomain mutations. Biochemistry and Molecular Biology Education, 2016,vol.44(1),pp.68-74. https://doi.org/10.1002/bmb.20927

[12] Heinzl, T., McCourt, T. Plymouth undergraduate research in mathematics, The Plymouth Student Scientist, 2015,vol.8(2),pp.1-5.

[13] Yang Zhidong, Chen Xiaoqiao. Exploration and research of academic contests and innovative talent training:Taking electronic discipline contests as an example, Experimental Technology and Management, 2016,vol.33(2),pp.14-23.

[14] Zhang, Ziyan. Exploration and analysis of training innovative talents approaches based on subject competition,Modern Education Management, 2014,vol.3,pp.61-65.

[15] Peng Miao,Ye Anqi, Zhu Jiehui. Research on significance of academic contest in study style construction of colleges and universities, Journal of Anhui Agricultural Sciences, 2015,vol. 43(8),pp.355-356.

[16] Shen Xiu, Sui Rongfang, Zeng Dewei. Construction and Practice of Discipline Contest Management System in Local Universities. Research and Exploration in Laboratory,2014,vol.33(11),pp.187-190.

[17] Zhuang Jianjun,Dong Ting,Zhang Zhijian,Ge Zhongqin,Zheng Xingfu,Cui Meng. Constructionoforganizationandtrainingsystemofelectronicdesign competition for college students in comprehensive universities,Experimental Technology and Management, 2016, vol.33(8),pp.168-172.

[18] Netemeyer, R. G., Krishnan, B., Pullig, C., Wang, G.,et al. Developing and validating measures of facets of customer-based brand equity,Journal of Business Research,2004,vol.57(2),pp.209-224. https://doi.org/10.1016/S0148-2963(01)00303-4

\section{Authors}

Hongwei Yue is with School of Information Engineering, Wuyi University, Jiangmen, China. His research interests include image processing (E-mail: yuehongwei420@163.com).

Ken Cai (Corresponding author) is with the School of Information Science and Technology, Zhongkai University of Agriculture and Engineering, Guangzhou, 510225, China (E-mail:icken@126.com).

Yibin Yu is with School of Information Engineering, Wuyi University, Jiangmen, China. His research interests include network and information security (E-mail: yuyibintony@163.com).

Yihong He is with School of Information Engineering, Wuyi University, Jiangmen, China. His research interests include image processing and multimedia courseware (E-mail: he_yihong@126.com).

Yingying Jin is a lecturer of School of Mathematics and Computational Science, Wuyi University, Jiangmen, China. Her research interests include general topology and multimedia courseware (E-mail: crescentlake@126.com).

Article submitted 20 May 2017. Published as resubmitted by the authors 25 June 2017. 